\begin{tabular}{|l|l|l||}
\hline \multicolumn{2}{|c|}{ PublisherInfo } \\
\hline \hline PublisherName & $:$ & BioMed Central \\
\hline \hline PublisherLocation & $:$ & London \\
\hline \hline PublisherImprintName & $:$ & BioMed Central \\
\hline \hline
\end{tabular}

\title{
Basic life support
}

\begin{tabular}{|l|l|l||}
\hline \multicolumn{2}{|c|}{ ArticleInfo } \\
\hline \hline ArticleID & $:$ & 4215 \\
\hline \hline ArticleDOI & $:$ & $10.1186 /$ ccf-2000-5899 \\
\hline \hline ArticleCitationID & $:$ & 5899 \\
\hline \hline ArticleSequenceNumber & $:$ & 74 \\
\hline \hline ArticleCategory & $:$ & Paper Report \\
\hline \hline ArticleFirstPage & $:$ & 1 \\
\hline \hline ArticleLastPage & $:$ & 3 \\
\hline \hline & & RegistrationDate : 2000-8-14 \\
\hline ArticleHistory & $:$ & OnlineDate \\
\hline \hline ArticleCopyright & $:$ & Current Science Ltd2000-8-14 \\
\hline \hline ArticleGrants & $:$ & \\
\hline \hline ArticleContext & $:$ & 1305422 \\
\hline \hline
\end{tabular}




\title{
Keywords
}

\author{
Cardiopulmonary resuscitation, outcome
}

\section{Comments}

Laboratory work has been summarised by a special report from the Ventilation Working Group of the Basic Life Support and Pediatric Life Support Subcommittees of the American Heart Association (Becker et al, Circulation 1997, 96:2102-2112). The summary concluded that mouth-to-mouth ventilation may not be necessary during the first few minutes of a witnessed cardiac arrest. This new and impressive study by workers in Seattle goes some way towards supporting this view; bystander initiated cardiac compressions (CC) alone may have a survival advantage over chest compressions plus mouthto-mouth ventilation (CCMV), although the results aren't statistically significant. The results are of particular importance to Seattle as emergency services were on the scene within an average of $4 \mathrm{~min}$, and dispatcher-directed CPR was more likely to be implemented in the CC group because the instructions were shorter and simpler. In the CCMV group, emergency services were more likely to have arrived prior to commencement of instructions, and the bystander was more likely to give up the resuscitation attempt due to the complexity of these instructions. The authors did not perform an intention-to-treat analysis (for valid reasons), and they accept that evidence is lacking in that it failed to show any benefit of providing CPR instructions prior to the arrival of the emergency services. Since the risks and costs of providing instructions are minimal, it seems reasonable to continue with this policy. Although CC alone is more likely to be insufficient when the accident location is some distance from the emergency services, it may save lives when the emergency services can respond rapidly, as bystanderinitiated resuscitation is more likely to happen.

\section{Introduction}

Management of out-of-hospital cardiac arrest impacts on the ICU as survivors frequently require organ support for variable periods. The quality of out-of-hospital CPR may also influence neurological outcome; we have all cared for patients who have eventually been successfully resuscitated following prolonged periods without CPR, but have suffered severe hypoxic brain damage as a result. This study is therefore of interest to the ICU physician because it investigates ways of improving bystander-initiated CPR before the arrival of the emergency services. 


\section{Methods}

- Prospective, randomised trial in which telephone dispatchers gave bystanders instructions for either $\mathrm{CC}$ or $\mathrm{CCMV}$

- Primary outcome was survival to hospital discharge

- Study period 1992-1998; location Seattle-King County, Washington, USA

\section{Results}

During this period there were 1296 randomised episodes of cardiac arrest, but 776 were excluded for three main reasons: absence of cardiac arrest; cardiac arrest due to drug overdose,alcohol intoxication or CO poisoning; and advanced life support notperformed. The remaining 520 cases were assigned to either CCMV (279) or CC (241). Baseline patient and episode characteristics were similar. The average time to arrival of the emergency services was $4 \mathrm{~min}$. Survival to hospital discharge was $10.4 \%$ for CCMV and $14.6 \%$ for CC $(P=0.18)$. Dispatcher instructions were completely delivered in $62 \%$ for CCMV and $81 \%$ for CC $(P=0.005)$. Arrival of the emergency services was the principal reason for incomplete instruction delivery. Bystanders receiving instructions for CCMV were more likely to give up because of the complexity of the instructions than bystanders receiving instructions for CC $(7.2 \% \mathrm{vs}$ $2.9 \%$.

\section{References}

1. Hallstrom A, Cobb L, Johnson E, Copass M: Cardiopulmonary resuscitation by chest compression alone or with mouth-to-mouth ventilation. N Engl J Med. 2000, 342: 1546-1553.

This PDF file was created after publication. 